\title{
Quantum Statistical Calculation of the Entropy of Formation of the Benzene Excimer
}

\author{
By
}

\author{
U. STEINER
}

Institut für Physikalische Chemie der Universität Stuttgart

\author{
With 4 figures
}

Auf quanten-statistischer Grundlage und unter Benutzung der Ergebnisse einer vorliegenden ,Extended Hückel"-Rechnung wird versucht, die Bildungsentropie des Benzol-Excimeren zu berechnen. Für Standardbedingungen $\left(25^{\circ} \mathrm{C}\right.$ und Konzentration von $1 \mathrm{Mol} / \mathrm{l}$ als ideales Gas) ergibt sich ein Wert von $\Delta S^{0}=-23.71 \mathrm{cal} / \mathrm{Grd} \cdot$ Mol. Der experimentelle Wert in Lösung ist - $29.6 \mathrm{cal} /$ Grd $\cdot$ Mol.

The entropy of formation of the benzene excimer was calculated from quantum statistical principles using data of an Extended Hückel calculation. For standard conditions $\left(25^{\circ} \mathrm{C}\right.$, concentration of $1 \mathrm{M}$, ideal gas state) the result is $\Delta S^{0}=-23.71$ e.u., which compares with an experimental value in solution of $-29.6 \mathrm{e.u}$.

\section{Introduction}

Many aromatic compounds are capable of forming dimers consisting of one excited and one unexcited molecule, the so called excimers, a process which can be detected by a change of the fluorescence spectrum when the concentration is increased ${ }^{1}$. At temperatures which are not too low an equilibrium is established. From the equilibrium constant and its temperature dependence the thermodynamic data of the excimer formation can be obtained.

Entropy data can be calculated by the usual methods of statistical mechanics, when the geometrical and dynamical data of a molecule are known. For excimers, however, these are not available experimen-

\footnotetext{
1 Tн. Förster, Angew. Chem. 81 (1969) 364.
} 
tally and so must be obtained from quantum chemical calculations. Among all theoretical work known to us an "Extended Hückel"Theory calculation on dimers of benzene by SRINIVASan, Russel and MoGlyns (S.R.G.) ${ }^{2}$ is the only one from which all parameters for the internal motions of the benzene excimer can be taken.

\section{General remarks on the method of entropy calculation}

The entropy of formation of the excimer $\Delta S$ is the change in entropy according to the reaction:

$$
A^{*}+A \rightarrow(A A)^{*}
$$

where $A^{*}$ and $A$ are the excited and unexcited monomer respectively, and $(A A)^{*}$ is the excimer. The standard value $\Delta S^{0}$ refers to a temperature of $298.15^{\circ} \mathrm{K}$ and to a concentration of $1 \mathrm{ML}$ for each participant of the reaction. The quantum statistical calculation accounts for a hypothetical excimer formation in the gas phase.

Within the excimer the benzene rings are considered as rigid hexagons, which is equivalent to the assumption that excimer formation does not influence the internal vibrations of the benzene rings.

The excited state geometry of benzene is assumed to be the same as in the ground state. The six internal coordinates will be transformed to a set, in which four can be regarded as independent of others and two are coupled together. The following formulae will be applied to calculate the contributions of the various degrees of freedom to the entropy: ( $k$ : Boltzmann's constant, $R$ : ideal gas constant, $h$ : Planck's constant, $N:$ Avogadro's number, $T$ : absolute temperature, $M$ : molecular weight, $v$ : volume).

Entropy of translation:

$$
S_{t}=R \cdot \ln \frac{v \cdot e^{5 / 2}(2 \pi M k T)^{3 / 2}}{N^{S / 2} \cdot h^{3}} .
$$

Entropy of rotation (nonlinear molecule):

$$
S_{r}=R \cdot \ln \frac{8 \pi^{2} \sqrt{8 \pi^{3} I_{1} I_{2} I_{3}(e k T)^{3}}}{\sigma \cdot h^{3}} .
$$

$I_{1}, I_{2}, I_{3}$ : principal moments of inertia, $\sigma$ : symmetry number.

2 B. N. Srinivasan, J. V. Rugsel and S. P. McGlyni, J. chem. Physics 48 (1968) 1931. 
Entropy of a harmonic oscillator:

$$
S_{v}=R \cdot\left(\frac{\Theta}{T\left(e^{\Theta / T}-1\right)}-\ln \left(1-e^{-\Theta / T}\right)\right) .
$$

$\Theta$ : characteristic temperature.

Entropy of internal rotation:

$$
S_{i r}=R \cdot \ln \frac{2 \pi \sqrt{2 \pi I_{i} e k T}}{\sigma_{i} \cdot h} .
$$

$I_{i}:$ reduced moment of inertia, $\sigma_{i}:$ internal symmetry number. The contributions of other degrees of freedom are calculated directly from the energy levels by the expression:

$$
S_{i}=R \cdot\left(\ln \Sigma e^{-\varepsilon_{i} / k T}+\sum \varepsilon_{i} e^{-\varepsilon_{i} / k T} / k T \cdot \sum e^{-\varepsilon_{i} / k T}\right)
$$

where the summation has to be extended to the dissociation energy of the excimer.

For the entropy of the rigid monomers, using $M=78.12 \mathrm{~g}, \sigma=12$, $I_{1}=I_{2}=B=147.59 \cdot 10^{-40} \mathrm{~g} \cdot \mathrm{cm}^{2} \quad$ (Ref. 3$), \quad I_{3}=I_{1}+I_{2}=A=2 B$, equations (1) and (2) yield: $S_{t}^{0}=32.628$ e.u., $S_{r}^{0}=20.723$ e.u. So $S_{\text {mono }}^{0}=53.351 \mathrm{e} . \mathbf{u}$.

\section{Geometry and dynamics of the benzene excimer}

As in the paper of S.R.G. our reference configuration is a configuration of $D_{6 h}$ symmetry (see Fig. 1).

The coordinates of the centers of gravity of the monomer components $x_{1,2}, y_{1,2}, z_{1,2}$ are $0,0, \pm \varrho$. The axes of symmetry are parallel to the coordinate axes. Configurational changes with respect to the reference configuration may be expressed by changes of the coordinates of the centers of gravity and by (small) rotations $\alpha_{1,2}, \beta_{1,2}, \gamma_{1,2}$ around the symmetry axes of the monomers. This description is unambiguous for small deviations from the reference configuration, so that we can avoid the tedious usage of Eulerian angles in this case. The state of motion of the excimer may then be described by the velocities $\dot{x}_{1,2}$, $\dot{y}_{1,2}, \dot{z}_{1,2}$ and by the angular velocities $\dot{\alpha}_{1,2}, \dot{\beta}_{1,2}, \dot{\gamma}_{1,2}$. So for the kinetic energy $T$ we can write the relation:

$$
\begin{aligned}
2 T & =m\left(\dot{x}_{1}{ }^{2}+\dot{y}_{1}{ }^{2}+\dot{z}_{1}{ }^{2}+\dot{x}_{2}{ }^{2}+\dot{y}_{2}{ }^{2}+\dot{z}_{2}{ }^{2}\right)+B\left(\dot{\alpha}_{1}{ }^{2}+\dot{\alpha}_{2}{ }^{2}+\dot{\beta}_{1}{ }^{2}+\dot{\beta}_{2}{ }^{2}\right) \\
& +A\left(\dot{\gamma}_{1}{ }^{2}+\dot{\gamma}_{1}{ }^{2}\right)
\end{aligned}
$$

where $m=M / N$ is the mass of the monomer.

3 B. P. StorchefF, Current Sci. [Bangalore] 2 (1958) 1. 


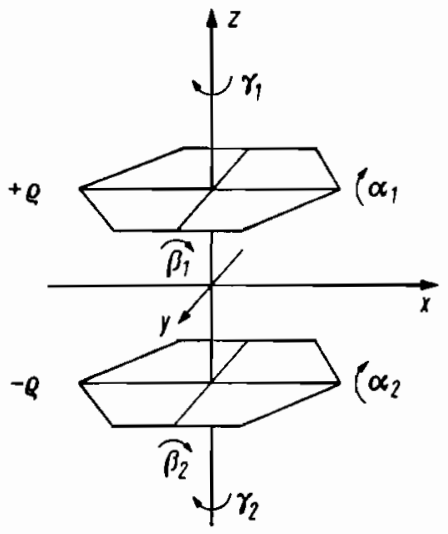

Fig. 1. $D_{6 n}$ reference configuration and definition of the coordinates

The coordinates of the monomers can be replaced by the external and internal coordinates of the excimer. As external coordinates we use the cartesian coordinates $X, Y, Z$ of the center of gravity of the excimer and the angles $\Phi_{x}, \Phi_{y}, \Phi_{z}$ for the rotations around the axes of the coordinate system, by which the inertia ellipsoid of the excimer is brought from the reference position to the new position.

The internal coordinates are those used by S.R.G.: parallel displacements $\Delta x, \Delta y, \Delta z$ and angles of internal rotations $\Theta_{x}, \Theta_{y}, \Theta_{z}$ by which the axes of component 2 are made parallel to the corresponding axes of component 1 . The various deformations of the excimer are shown in Fig. 2. $\Delta x$ and $\Delta y$ represent shear strains, $\Delta z$ a stretching of the excimer bond. $\Theta_{x}$ and $\Theta_{y}$ tilt the planes of the components against each other, $\Theta_{z}$ rotates the monomers in opposite directions around the six fold axis of symmetry.

The transformation to the new coordinates yields for the components of the velocities:

$$
\begin{gathered}
\dot{X}=\frac{1}{2}\left(\dot{x}_{1}+\dot{x}_{2}\right) \quad \dot{Y}=\frac{1}{2}\left(\dot{y}_{1}+\dot{y}_{2}\right) \quad \dot{Z}=\frac{1}{2}\left(\dot{z}_{1}+\dot{z}_{2}\right) \\
\dot{\Theta}_{x}=\dot{\alpha}_{1}-\dot{\alpha}_{2} \quad \dot{\Theta}_{1}=\dot{\beta}_{2}-\dot{\beta}_{2} \quad \dot{\Theta}_{z}=\dot{\gamma}_{1}-\dot{\gamma}_{2} \\
\Delta \dot{x}=\dot{x}_{1}-\dot{x}_{2}-\varrho\left(\dot{\beta}_{1}+\dot{\beta}_{2}\right) \quad \Delta \dot{y}=\dot{y}_{1}-\dot{y}_{2}-\varrho\left(\dot{\alpha}_{1}+\dot{\alpha}_{2}\right) \quad \Delta \dot{z}=\dot{z}_{1}-\dot{z}_{2} \\
2\left(B+m \varrho^{2}\right) \dot{\Phi}_{x}=m \varrho\left(\dot{y}_{1}-\dot{y}_{2}\right)+B\left(\dot{\alpha}_{1}+\dot{\alpha}_{2}\right) \\
2\left(B+m \varrho^{2}\right) \dot{\Phi}_{y}=m \varrho\left(\dot{x}_{1}-\dot{x}_{2}\right)+B\left(\dot{\beta}_{1}+\dot{\beta}_{2}\right)
\end{gathered}
$$

Equation (7) and (8) are obvious. The equations (9) result from the fact that, for example, the rotations $\beta_{1}$ and $\beta_{2}$ of the two monomer 

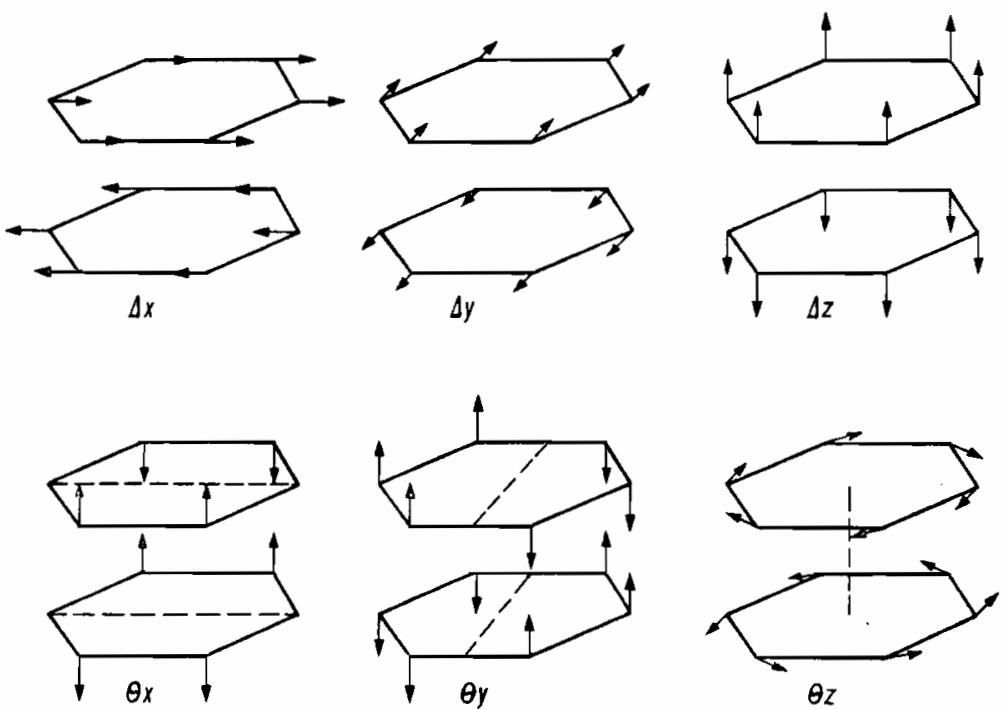

Fig. 2. Internal coordinates of the excimer

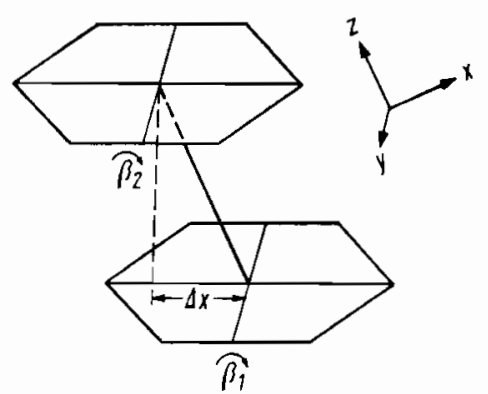

Fig. 3. Connection between parallel displacement and rotation of the monomers

components are not only involved in the rotations $\Theta_{y}$ and $\Phi_{y}$ but also give a contribution $\Delta x=-\varrho\left(\beta_{1}+\beta_{2}\right)$ to the shear strain (see Fig. 3). On the other hand purely parallel displacements of the monomer components contribute to the angular momentum of the excimer [eq. (10)].

Solution of equations (9) and (10) leads to:

$\dot{x}_{1}-\dot{x}_{2}=2 \varrho \dot{\Phi}_{y}+\Delta \dot{x} /\left(1+\frac{m \varrho^{2}}{B}\right) ; \dot{y}_{1}-\dot{y}_{2}=2 \varrho \dot{\Phi}_{x}+\Delta \dot{y} /\left(1+\frac{m \varrho^{2}}{B}\right)$

$\dot{\alpha}_{1}+\dot{\alpha}_{2}=2 \dot{\Theta}_{x}-m \varrho \Delta \dot{y} /\left(B+m \varrho^{2}\right) ; \dot{\beta}_{1}+\dot{\beta}_{2}=2 \dot{\Theta}_{y}-m \varrho \Delta \dot{x} /\left(B+m \varrho^{2}\right)$ 
Insertion of equations (7), (8), $\left(9^{\prime}\right)$ and $\left(10^{\prime}\right)$ into equation (6) yields a purely quadratic form of the kinetic energy in terms of the internal and external velocity components.

$$
\begin{aligned}
2 T & =2 m\left(\dot{X}^{2}+\dot{Y}^{2}+\dot{Z}^{2}\right)+2\left(B+m \varrho^{2}\right)\left(\dot{\Phi}_{x^{2}}+\dot{\Phi}_{y}^{2}\right)+2 A \dot{\Phi}_{z}^{2} \\
& +\frac{m B}{2\left(B+m \varrho^{2}\right)}\left(\Delta \dot{x}^{2}+\Delta \dot{y}^{2}\right)+\frac{m}{2} \Delta \dot{z}^{2}+\frac{B}{2}\left(\dot{\Theta}_{x^{2}}+\dot{\Theta}_{y^{2}}\right)+\frac{A}{2} \dot{\Theta}_{z}{ }^{2} .
\end{aligned}
$$

This expression is exact not only for the reference configuration but for all configurations with an arbitrary internal rotation $\Theta_{z} \neq 0$, if the rotational axes of component 2 are always defined parallel to the symmetry axes of component 1 . It is approximately valid for configurations with small displacements $\Delta x, \Delta y, \Delta z$, and small inclinations $\Theta_{x}$ and $\Theta_{y}$.

N. The values of $M=N \cdot m, A$ and $B$ have already been given in II. For half of the equilibrium distance of the monomer planes we use the value calculated by S.R.G.: $\varrho=1.75 \AA$.

For the dependence of the potential energy of the excimer on its internal coordinates the results of S.R.G. suggest the following expression:

$2 V=\varkappa\left(\Delta x^{2}+\Delta y^{2}\right)+2 D\left(1-e^{-\alpha(\Delta z-2 \varrho)}\right)^{2}+f\left(\Theta_{x}, \Theta_{y}\right)+\varepsilon \cdot \sin 6 \Theta_{z}$.

The shear strains $\Delta x$ and $\Delta y$ are treated as harmonic oscillations with equal force constants $x$, whereas the strongly anharmonic stretching or breathing vibration $\Delta z$ is treated with a Morse potential. The weak hindrance of the internal rotation $\Theta_{z}$ is accounted for by a sinusoidal potential with a six fold symmetry axis. For the constants in equation (12) we use the following values (taken from S.R.G. Fig. 1-3):

$$
\begin{aligned}
& x=0.120 \mathrm{eV} / \AA=1922 \mathrm{erg} / \mathrm{cm}^{2} \\
& D=0.14 \mathrm{eV} \quad=2.24 \cdot 10^{-13} \mathrm{erg}=3.22 \mathrm{kcal} \\
& a=1.92 \AA^{-1} \\
& \varepsilon=0.01 \mathrm{eV} \quad=0.23 \mathrm{kcal} \text {. }
\end{aligned}
$$

The motions according to the coordinates $\Theta_{x}$ and $\Theta_{y}$ may be described by tilting vibrations. The corresponding potential is not of a simple form, however, and at this point shall be represented by the general function $f\left(\Theta_{x}, \Theta_{y}\right)$. The reason for this is, that in the equilibrium configuration of the excimer the planes of the components are tilted against each other by about $5.5^{\circ}$, independently of the azimuth of their 
inclination, so that we have a double minimum potential for the two tilting vibrations.

The data of S.R.G. suggest to express the function $f\left(\Theta_{x}, \Theta_{y}\right)$ by two new variables $\Omega$ and $\varphi$, which are the angle of the inclination of the two planes against each other, and its azimuth respectively. For small values of $\Theta_{x}$ and $\Theta_{y}$ we have the transformation equations:

$$
\Theta_{x}=\Omega \cdot \sin \varphi \quad \Theta_{y}=\Omega \cdot \cos \varphi .
$$

Then equations (11) and (12) are changed to:

$$
\begin{aligned}
2 T & =2 m\left(\dot{X}^{2}+\dot{Y}^{2}+\dot{Z}^{2}\right)+2\left(B+m \varrho^{2}\right)\left(\dot{\Phi}_{x^{2}}+\dot{\Phi}_{y}{ }^{2}\right)+2 A \dot{\Phi}_{z}{ }^{2} \\
& +\frac{m B}{2\left(B+m \varrho^{2}\right)}\left(\Delta \dot{x}^{2}+\Delta \dot{y}^{2}\right)+\frac{m}{2} \Delta \dot{z}^{2}+\frac{B}{2} \dot{\Omega}^{2}+\frac{B}{2} \dot{\Omega}^{2} \dot{\varphi}^{2}+\frac{A}{2} \dot{\Theta}_{z}^{2}
\end{aligned}
$$

$2 V=x\left(\Delta x^{2}+\Delta y\right)^{2}+2 D\left(1-e^{-\alpha(\Delta z-2 o)}\right)^{2}+f(\Omega)+\varepsilon \cdot \sin 6 \Theta_{z}$.

In equation $\left(\mathbf{1 1}^{\prime}\right)$ there occurs a mixed product of the coordinates $\Omega$ and $\varphi$, so the entropy contribution due to these coordinates cannot be separated. We solve the corresponding eigenvalue problem, with the Hamiltonian:

$$
H_{\Omega, \varphi}=-\frac{\hbar^{2}}{B}\left(\frac{\partial^{2}}{\partial \Omega^{2}}+\frac{1}{\Omega} \frac{\partial}{\partial \Omega}+\frac{1}{\Omega^{2}} \frac{\partial^{2}}{\partial \varphi^{2}}\right)+V(\Omega) .
$$

The corresponding eigenfunctions are of the form:

$$
\Psi_{m, n}(\Omega, \varphi)=\psi_{m, n}(\Omega) e^{i n \varphi}
$$

with $\psi_{m, n}$ as the eigenfunctions of the ordinary differential equation:

$$
\psi_{m, n}^{\prime \prime}+\frac{1}{\Omega} \psi_{m, n}^{\prime}-\left[\frac{B}{\hbar^{2}}\left(V(\Omega)-\varepsilon_{m, n}\right)+\frac{n^{2}}{\Omega^{2}}\right] \psi_{m, n}=0 .
$$

The shape of the potential $V(\Omega)$ is given in Fig.4, according to S.R.G. As it cannot be well fitted to potentials which have been treated in the literature 4,5 we chose an approximation by a step function (see Fig.4):

$$
\begin{aligned}
& V(\Omega)=V_{0} \text { for } \Omega \leq \Omega_{1} \\
& V(\Omega)=0 \text { for } \Omega_{1}<\Omega<\Omega_{2} \\
& V(\Omega)=\infty \text { for } \Omega \geq \Omega_{2} .
\end{aligned}
$$

The two step functions correspond to the values $V_{0}=0.025 \mathrm{eV}$, $\Omega_{2}=8.3^{\circ}$ and $\Omega_{1}=3.6^{\circ}(\mathrm{a}), 4.4^{\circ}(\mathrm{b})$. For the sake of error estimation the case of $V_{0}=0 . \mathrm{eV}$ is also treated (c).

4 W. R. Thorson and I. Nakagawa, J. chem. Physics 33 (1960) 994.

5 R. N. Dixon, Trans. Faraday Soc. 60 (1964) 1363. 


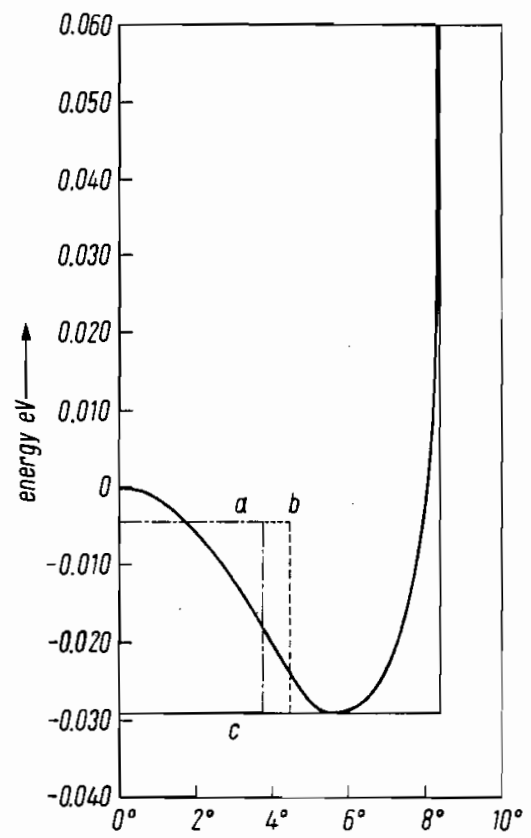

Fig. 4. Potential energy as a function of the tilting angle $\left(\Theta_{x}\right.$ or $\left.\Theta_{y}\right)$ according to S.R.G. and approximating step functions

The solutions of equation (15) are:

$$
\begin{array}{lr}
\psi_{m, n}(\Omega)=C_{1} J_{n}\left(\sqrt{e_{m, n}-v_{0}} \Omega\right) & \left(\Omega \leqslant \Omega_{1}\right) \\
\psi_{m, n}(\Omega)=C_{2} J_{n}\left(\sqrt{e_{m, n}} \Omega\right)+C_{3} Y_{n}\left(\sqrt{e_{m, n}} \Omega\right) & \left(\Omega_{1} \leqslant \Omega \leqslant \Omega_{2}\right)
\end{array}
$$$$
\left(\Omega_{1} \leqslant \Omega \leqslant \Omega_{2}\right)(17)
$$

with

$$
v_{0}=\frac{B V_{0}}{\hbar^{2}}, e_{m, n}=\frac{B \varepsilon_{m, n}}{\hbar^{2}}
$$

Table 1. Energy levels for the potentials $a, b$ and $c$

\begin{tabular}{lrllll}
\hline \multicolumn{2}{l}{ quantum numbers } & & \multicolumn{3}{l}{ potential } \\
\cline { 5 - 6 }$m$ & $n$ & & $a$ & $b$ & $c$ \\
\hline 0 & 0 & 0.023 & 0.028 & 0.013 \\
0 & \pm 1 & 0.038 & 0.042 & 0.032 \\
0 & \pm 2 & 0.061 & 0.065 & 0.058 \\
1 & 0 & 0.080 & 0.081 & 0.068 \\
0 & \pm 3 & 0.092 & 0.095 & 0.089 \\
1 & \pm 1 & 0.122 & 0.124 & 0.110 \\
0 & \pm 4 & 0.129 & 0.131 & 0.126
\end{tabular}

Energy in oV. 
$J_{n}$ and $Y_{n}$ are the Bessel functions of the first and second kind. The conditions $\psi=0$ at $\Omega_{2}$ and continuity of $\psi$ and $\psi^{\prime}$ at $\Omega_{1}$ lead to the eigenvalues $e_{m, n}$ from which the $\varepsilon_{m, n}$ can be calculated. These are presented in Table 1 up to the dissociation energy of the excimer.

\section{Entropy of the benzene excimer}

From equations $\left(11^{\prime}\right)$ and $\left(12^{\prime}\right)$ and the numerical values of the constants the following contributions of the various degrees of freedom to the entropy can be calculated:

a) Translation $(X, Y, Z$ with mass $2 m=2 M / N)$ $S_{t}{ }^{0}=34.69$ e.u.

b) Rotation (with moments of inertia $2\left(B+m \varrho^{2}\right)$ for $\Phi_{x}$ and $\Phi_{y}$, and $2 A$ for $\Phi_{z}$ )

$S_{r}^{0}=25.39$ e. u.

c) Shear vibrations ( $\Delta x$ and $\Delta y$ with reduced mass $m B / 2\left(B+m \varrho^{2}\right)$ and force constant $x$ )

$S_{v x}^{0}=S_{v y}^{0}=4.59 \mathrm{e} . \mathrm{u}$.

d) Breathing vibration ( $\Delta z$ with reduced mass $m / 2$, Morse potential) Entropy calculated according to equation (5):

$S_{v z}^{0}=4.38$ e.u.

e) Internal rotation $\left(\Theta_{z}\right.$, reduced moment of inertia $A / 2=B$, potentialbarrier $\varepsilon$ ).

Calculation of a free internal rotation yields $S_{r i}^{0}=5.52_{2}$ e.u. For the hindered rotation the result is (according to a table of PItzer and GWINN ${ }^{6}$ ):

$S_{r i}^{0}=5.50_{5}$ e.u.

f) Tilting vibrations $\left(\Theta_{x}, \Theta_{y}\right.$ or $\left.\Omega, \varphi\right)$

With the energy levels of Table 1 equation (5) yields:

$$
\begin{aligned}
S_{\Omega, \varphi}^{0} & =3.79_{8} \text { e.u. for potential a } \\
& =\mathbf{3 . 8 8 _ { 8 }} \text { e.u. for potential b } \\
& =\mathbf{3 . 7 4 _ { 4 }} \text { e.u. for potential c }
\end{aligned}
$$

${ }^{6}$ K. S. Pitzer and W. D. Gwinn, J. chem. Physics 10 (1942) 428. 
Summation of all contributions gives a total of the excimer entropy of

$$
S_{\mathrm{exc}}^{0}=82.99 \mathrm{e} . \mathrm{u} .
$$

The entropy of formation of the excimer is:

$$
\Delta S^{0}=S_{\mathrm{exc}}^{0}-2 S_{\mathrm{mono}}^{0}=-23.71 \mathrm{e} . \mathrm{u} .
$$

\section{Discussion}

At present thre are no excimer data in the gas phase known from experiment. The entropy of benzene excimer formation calculated in this work, must therefore be compared with data from solution measurements. To justify such a comparison a number of $\Delta S^{0}$ values for EDA complexes in the gas phase and in solution are presented in Table 2.

For the complexes of the aromatic molecules with tetracyanoethylene (TCNE) the $\Delta S^{0}$ values in solution are a little more positive (by max. 3.5 e.u.) than in the gas phase. For complexes with $\mathrm{SO}_{2}$ and $\mathrm{I}_{2}$ as acceptors the solution values are more negative by the same order of magnitude.

A thermodynamic argument may be used to estimate the difference in $\Delta S^{0}$ between gas phase and solution reaction.

a Values in the gas phase were obtained above $100^{\circ} \mathrm{C}$, standard state $1 \mathrm{M}$. Values in solution were obtained at room temperature.

b $\Delta H$ and $\Delta U$ are different in the gas phase by $R T \approx 0,8 \mathrm{kcal}$. To be correct one should compare $\Delta U$ values in gas phase and solution.

c Tetracyanoethylene.

d Calculated by HaNAzAKI? from data of the reference quoted.

e The corresponding values, given by $K_{R O L L}{ }^{10}$ are smaller by 5.6 e.u. The explanation for this discrepancy is that Kroll takes the constants $K_{x}$ of Merrifield and Phillips ${ }^{9}$ for $K_{c}$ (compare also Hanazaki ${ }^{7}$ ).

7 I. Hanazaki, J. physic. Chem. 76 (1972) 1982.

8 G. Briegles, J. Czekalla and G. Reuss, Z. physik. Chem. Neue Folge 30 (1961) 333.

${ }_{9}$ R. E. Merrifield and W. D. Phillips, J. Amer. chem. Soc. 80 (1958) 2778.

${ }_{10}$ M. Kroll, J. Amer. chem. Soc. 90 (1968) 1097.

11 F. S. Booth, F.S. Dainton and K. J. Ivin, Trans. Faraday Soc. 65 (1959) 1293.

12 J. M. Goodenow and M. Tamres, J. chem. Physics 43 (1965) 3393.

13 M. Tamres and S. Searles, Jr., J. physic. Chem. 66 (1962) 1099. 
Table 2. Thermodynamic data of CT-complexes in the gas phase and in solution

\begin{tabular}{|c|c|c|c|c|c|}
\hline CT-complex & solvent & $-\Delta H[\mathrm{kcal}]^{\mathrm{a}, \mathrm{b}}$ & $-\Delta S^{0}[\text { e.u. }]^{\mathrm{a}}$ & Lit. & Ref. \\
\hline $\begin{array}{l}\text { Benzene- } \\
\text { TCNE c }\end{array}$ & $\begin{array}{l}\text { gas phase } \\
\mathrm{CCl}_{4} \\
\mathrm{CH}_{2} \mathrm{Cl}_{2}\end{array}$ & $\begin{array}{l}6.6 \pm 0.3 \\
3.12 \\
2.3\end{array}$ & $\begin{array}{l}12.2 \pm 0.7 \\
10.6 \\
11.9\end{array}$ & $\begin{array}{l}\text { HaNazaki } \\
\text { Briggleb d et al. } \\
\text { MerRifield and } \\
\text { Phillips }\end{array}$ & $\begin{array}{l}7 \\
8\end{array}$ \\
\hline Toluene-TCNE & $\begin{array}{l}\text { gas phase } \\
\mathrm{CH}_{2} \mathrm{Cl}_{2}\end{array}$ & $\begin{array}{l}7.22 \pm 0.07 \\
2.72\end{array}$ & $\begin{array}{l}13.6 \pm 0.2 \\
12.1\end{array}$ & $\begin{array}{l}\text { HaNAzaki } \\
\text { MERrifield and } \\
\text { Phillips }\end{array}$ & 7 \\
\hline $\begin{array}{l}\text { Naphthalene- } \\
\text { TCNE }\end{array}$ & $\begin{array}{l}\text { gas phase } \\
\mathrm{CCl}_{4}\end{array}$ & $\begin{array}{l}7.67 \pm 0.09 \\
3.84\end{array}$ & $\begin{array}{l}11.9 \pm 0.2 \\
10.8\end{array}$ & $\begin{array}{l}\text { HANAZAKI } \\
\text { BRIEGLEB }^{d} \text { et al. }\end{array}$ & $\begin{array}{l}7 \\
8\end{array}$ \\
\hline $\begin{array}{l}p \mathrm{Xy} \text { lene- } \\
\text { TCNE }\end{array}$ & $\begin{array}{l}\text { gas phase } \\
\mathrm{CH}_{2} \mathrm{Cl}_{2}\end{array}$ & $\begin{array}{l}8.1 \pm 0.5 \\
3.37\end{array}$ & $\begin{array}{l}15.5 \pm 2.0 \\
13.0 \mathrm{e}^{-}\end{array}$ & $\begin{array}{l}\text { KROLL } \\
\text { MERRIFIELD and } \\
\text { PHILLIPS }\end{array}$ & 10 \\
\hline $\begin{array}{l}\text { Mesitylene- } \\
\text { TCNE }\end{array}$ & $\begin{array}{l}\text { gas phase } \\
\mathrm{CH}_{2} \mathrm{Cl}_{2}\end{array}$ & $\begin{array}{l}9.9 \pm 0.5 \\
4.52\end{array}$ & $\begin{array}{l}18.7 \pm 2.0 \\
15.2^{\mathrm{e}}\end{array}$ & $\begin{array}{l}\text { Krolt } \\
\text { MERrifield and } \\
\text { Phillips }\end{array}$ & $\begin{array}{r}10 \\
9\end{array}$ \\
\hline Durene-TCNE & $\begin{array}{l}\text { gas phase } \\
\mathrm{CH}_{2} \mathrm{Cl}_{2}\end{array}$ & $\begin{array}{l}10.8 \pm 0.8 \\
5.07\end{array}$ & $\begin{array}{l}17.3 \pm 3.1 \\
14.8^{e^{-}}\end{array}$ & $\begin{array}{l}\text { KROLL } \\
\text { MERRIFIELD and } \\
\text { PHILILPS }\end{array}$ & 10 \\
\hline $\begin{array}{l}\text { tr-2-butene- } \\
\mathrm{SO}_{2}\end{array}$ & $\begin{array}{l}\text { gas phase } \\
n \text {-hexane }\end{array}$ & $\begin{array}{l}3.11 \pm 0.07 \\
1.37 \pm 0.12\end{array}$ & $\begin{array}{l}6.2 \pm 0.2 \\
9.55 \pm 0.5\end{array}$ & $\begin{array}{l}\text { HANAZAKI } \\
\text { BoOTH et al. }\end{array}$ & $\begin{array}{r}7 \\
11\end{array}$ \\
\hline \multirow[t]{3}{*}{$E t_{2} S-I_{2}$} & $\begin{array}{l}\text { gas phase } \\
\text { gas phase }\end{array}$ & $\begin{array}{l}8.3 \pm 0.5 \\
8.5 \pm 0.4\end{array}$ & $\begin{array}{l}14.2 \pm 1.9 \\
15.3 \pm 1.1\end{array}$ & $\begin{array}{l}\text { KROLL } \\
\text { GoODENow and } \\
\text { TAMRES }\end{array}$ & $\begin{array}{l}10 \\
12\end{array}$ \\
\hline & $n$-heptane & $8.9 \pm 0.6$ & $19.4 \pm 2.0$ & $\begin{array}{l}\text { GoodENow and } \\
\text { TAMRES }\end{array}$ & 12 \\
\hline & $n$-heptane & $8.3 \pm 0.2$ & $17.6 \pm 0.5$ & $\begin{array}{l}\text { GoODENow and } \\
\text { TAMRES }\end{array}$ & 12 \\
\hline \multirow[t]{2}{*}{$\begin{array}{l}\text { Tetrahydro- } \\
\text { thiophene- } I_{2}\end{array}$} & gas phase & $9.0 \pm 0.5$ & $14.2 \pm 1.6$ & KroLL & 10 \\
\hline & $n$-heptane & 7.8 & 15 & $\begin{array}{l}\text { TAMRES and } \\
\text { SEARIES }\end{array}$ & 13 \\
\hline
\end{tabular}


The entropy of solution of ideal benzene vapor in an ideal solution may be calculated as the difference of the corresponding values for the entropy of vaporization and the entropy of mixing of liquid benzene with the solvent, according to:

$$
S_{v / s}=-R \ln x-\frac{L_{p}}{T}+R \ln \frac{p}{p_{e}}
$$

( $x$ mole fraction of benzene in solution, $L_{p}$ molar heat of vaporization of liquid benzene, $p$ standard pressure of the vapor, $p_{e}$ equilibrium vapor pressure of benzene at $T$, absolute temperature).

Using $p=24.6$ at (concentration of $1 \mathrm{M}$ ) and $x=0.1$ ( $1 \mathrm{M}$ solution in solvent like cyclohexane) this equation yields for benzene at $25^{\circ} \mathrm{C}: S_{v / s}=-12.5$ e.u.

To obtain the corresponding value for the excimer one might use data of a molecule of similar size: e.g. pentamethylbenzene ${ }^{14}$. For the same standard conditions the result is $S_{v / s}=-22.5$ e.u. It might therefore be expected that $\Delta S^{0}$ should become more positive by about 2.5 e.u. when passing from the gas phase reaction to the reaction in ideal solution, which is in agreement with the behaviour of the aromatic-TCNE complexes.

For the formation of the benzene excimer in cyclohexane at $25^{\circ} \mathrm{C}$ a $\Delta S^{0}$ value of -20.3 e.u. is given by Briks et. al. ${ }^{15}$.

CUNDALL and ROBINSON ${ }^{16}$ showed that the calculation of this value from the experimental data is based on an erroneous assumption, namely that the radiative lifetimes of monomer and excimer should be temperature independent.

Measuring between $20^{\circ} \mathrm{C}$ and $60^{\circ} \mathrm{C}$ Cundall and Robinson observed a temperature dependence of the excimer radiative lifetime with an activation energy of $3.4 \mathrm{kcal}$. Using this result the enthalpy of excimer formation becomes $-8.2 \mathrm{kcal}$ and hence $\Delta S^{0}=R \ln K$ $+\frac{\Delta H}{T}=-29.6$ e. u.

Assuming that entropies of excimer formation in gas phase and solution may be compared, the theoretical value of -23.7 is somewhat too low. From this one may conclude that on average the force constants of the model ${ }^{2}$ are too low.

14 F. H. MadDodgall and L. I. Smith, J. Amer. chem. Soc. 52 (1930) 1998.

15 J. B. Brrks, C. L. Braga and M. D. Lumb., Proc. Roy. Soc. [London], Ser. A 283 (1965) 83.

16 R. B. Cundali and D. A. Robinson, Faraday Trans. II, 7 (1972) 1133. 
It should be emphasized, however, that agreement with the experimental value is far better in the case of the entropy than of the enthalpy. The model gives a dissociation energy of about $3.2 \mathrm{kcal}$. For the binding energy of the excimer in the gas phase one should expect a value which is by $3-4 \mathrm{kcal}$ higher than in solution (see Table 2), thus about $12 \mathrm{kcal}$ in all. So the model gives only $25 \%$ of the binding energy but about $75 \%$ of the reaction entropy. This would suggest that not only the energy but also the entropy may be a valuable test for quantum chemical calculations of short lived molecules.

\section{Acknowledgement}

The author is deeply indebted to the late Prof. Dr. Tr. Förster for suggesting this work and for his continuous interest in its progress. 